University of Nebraska - Lincoln

DigitalCommons@University of Nebraska - Lincoln

Publications, Agencies and Staff of the U.S.

Department of Commerce

U.S. Department of Commerce

2004

\title{
MONITORING POLYNUCLEAR AROMATIC HYDROCARBONS IN AQUEOUS ENVIRONMENTS WITH PASSIVE LOW-DENSITY POLYETHYLENE MEMBRANE DEVICES
}

\author{
Mark G. Carls \\ National Oceanic and Atmospheric Administration, mark.carls@noaa.gov \\ Larry G. Holland \\ National Oceanic and Atmospheric Administration \\ Jeffrey W. Short \\ National Oceanic and Atmospheric Administration \\ Ron A. Heintz \\ National Oceanic and Atmospheric Administration \\ Stanley D. Rice \\ National Oceanic and Atmospheric Administration
}

Follow this and additional works at: https://digitalcommons.unl.edu/usdeptcommercepub

Part of the Environmental Sciences Commons

Carls, Mark G.; Holland, Larry G.; Short, Jeffrey W.; Heintz, Ron A.; and Rice, Stanley D., "MONITORING POLYNUCLEAR AROMATIC HYDROCARBONS IN AQUEOUS ENVIRONMENTS WITH PASSIVE LOWDENSITY POLYETHYLENE MEMBRANE DEVICES" (2004). Publications, Agencies and Staff of the U.S. Department of Commerce. 248.

https://digitalcommons.unl.edu/usdeptcommercepub/248

This Article is brought to you for free and open access by the U.S. Department of Commerce at DigitalCommons@University of Nebraska - Lincoln. It has been accepted for inclusion in Publications, Agencies and Staff of the U.S. Department of Commerce by an authorized administrator of DigitalCommons@University of Nebraska - Lincoln. 


\title{
MONITORING POLYNUCLEAR AROMATIC HYDROCARBONS IN AQUEOUS ENVIRONMENTS WITH PASSIVE LOW-DENSITY POLYETHYLENE MEMBRANE DEVICES
}

\author{
Mark G. Carls, * Larry G. Holland, Jeffrey W. Short, Ron A. Heintz, and Stanley D. Rice \\ National Oceanic and Atmospheric Administration, National Marine Fisheries Service, Alaska Fisheries Science Center, Auke Bay Laboratory, \\ 11305 Glacier Highway, Juneau, Alaska 99801, USA
}

(Received 14 July 2003; Accepted 3 November 2003)

\begin{abstract}
Low-density polyethylene membranes, typically filled with triolein, have been previously deployed as passive environmental samplers designed to accumulate nonpolar hydrophobic chemicals from water, sediments, and air. Hydrocarbons in such samplers, known as semipermeable membrane devices (SPMDs), diffuse through pores in the membranes and are trapped in the central hydrocarbon matrix, mimicking uptake by living organisms. Here, we describe laboratory and field verification that lowdensity polyethylene membrane devices (PEMDs) without triolein provide reliable, relatively inexpensive, time-integrated hydrocarbon sampling from water. For comparison, polynuclear aromatic hydrocarbon (PAH) uptake in SPMDs and pink salmon eggs also was studied. Total concentrations of PAH accumulated by PEMDs were highly correlated with concentrations in water $\left(r^{2} \geq\right.$ $0.99)$ and linear over the range tested $(0-17 \mu \mathrm{g} / \mathrm{L})$. Higher-molecular-mass PAH preferentially accumulated in PEMDs and in pink salmon eggs, but the source of oil in PEMDs remained identifiable. Accumulations of PAH were highly similar to those in SPMDs. The PEMDs retained approximately $78 \%$ of accumulated total PAH for $40 \mathrm{~d}$ in clean water. Thus, a simple plastic membrane can be conveniently used for environmental monitoring, particularly during situations in which contaminant concentrations are low (in the parts-per-billion range), variable, and intermittent.
\end{abstract}

Keywords-Polyethylene membrane devices Semipermeable membrane devices Polynuclear aromatic hydrocarbon Environmental monitoring

\section{INTRODUCTION}

Environmental water-quality sampling options for detection of organic hydrocarbons typically include direct extraction of water samples, monitoring of biological tissue, and passive chemical sampling devices. Direct measures of hydrocarbon concentrations in water relate directly to water-quality standards. However, discrete sampling can easily miss intermittent pulses of contaminants, or quantities may be less than the practical detection limits [1-3]. Mussels or other biological tissue may be used, if present and available, to monitor hydrocarbons, but compounds are typically actively or passively exported and often metabolized, reducing the probability of detection [3-5]. In addition, separation of trace-level contaminants from a biological matrix can be problematic. Passive sampling devices have emerged in recent years that have excellent detection sensitivity, integrate aqueous concentrations over time, and are cheaper and easier to analyze than biological tissue $[1,6,7]$.

Low-density polyethylene membranes, typically filled with triolein, have been successfully deployed as passive environmental samplers designed to accumulate nonpolar hydrophobic chemicals from water, sediments, and air (see, e.g., [1,8-11]). Hydrocarbons in such biomimetic samplers, known as semipermeable membrane devices (SPMDs), diffuse through pores in the polyethylene and are trapped in the central hydrocarbon matrix, mimicking uptake by living organisms (but without metabolism). For example, uptake of chlorinated hydrocarbon and pesticide congeners was similar in SPMDs, mussels, and fish $[6,10,12]$.

* To whom correspondence may be addressed (mark.carls@noaa.gov).
At low ambient concentrations of organic compounds, lowdensity polyethylene membrane devices (PEMDs) deployed without inclusion of the central hydrocarbon reservoir may be simpler and less expensive sampling devices compared to SPMDs yet provide the same benefits. Although the idea of using PEMDs is not novel, little research concerning them has been published in the primary literature (see, e.g., [13]). We suspected that PEMDs would not become saturated at total polynuclear aromatic hydrocarbon (TPAH) concentrations of a few micrograms per liter (e.g., $15 \mu \mathrm{g} / \mathrm{L}$, the legal waterquality limit in Alaska), suggesting the suitability of the simplified sampler design.

Our objective, therefore, was to verify the effectiveness and reliability of simple PEMDs to sample low concentrations of polynuclear aromatic hydrocarbons (PAH) with a series of laboratory and field tests. Motivating factors were the 1989 Exxon Valdez oil spill, now more than a decade old, and concerns about petroleum hydrocarbon entry into watersheds proximal to urban areas. In both cases, we wished to determine if $\mathrm{PAH}$ was biologically available and could pose risks to sensitive organisms at sensitive life stages, such as pink salmon (Oncorhynchus gorbusha) embryos, and we recognized that such exposures likely were intermittent. Specifically, we compared PAH accumulation (concentration and composition) in PEMDs to that in treatment water and in pink salmon eggs, monitored PAH retention in PEMDs in clean or nearly clean water for up to $40 \mathrm{~d}$, and compared PEMD and SPMD performance in field environments where intermittent, low levels of PAH were expected. The influence of molecular mass on the accumulation and retention of PAHs in PEMDs and eggs was explored to further characterize hydrocarbon exchange and explain the differences between them. Size-related differences 
Table 1. Polynuclear aromatic hydrocarbon (PAH) analytes, abbreviations, deuterated surrogate references, molecular mass, and the $\log$ of the octanol-water partition coefficient $\left(K_{\mathrm{ow}}\right)^{\mathrm{a}}$

\begin{tabular}{|c|c|c|c|c|}
\hline PAH & Abbreviation & Surrogate & $\begin{array}{l}\text { Molecular } \\
\text { mass } \\
(\mathrm{g} / \mathrm{mol})\end{array}$ & $\log K_{\text {ow }}$ \\
\hline Naphthalene & No & 1 & 128.2 & 3.36 \\
\hline C-1 naphthalenes & N1 & 1 & 142.2 & 3.80 \\
\hline $\mathrm{C}-2$ naphthalenes & $\mathrm{N} 2$ & 2 & 156.2 & 4.30 \\
\hline C-3 naphthalenes & N3 & 2 & 170.3 & 4.80 \\
\hline C-4 naphthalenes & N4 & 2 & 184.3 & 5.30 \\
\hline Biphenyl & BIP & 2 & 154.2 & 3.80 \\
\hline Acenaphthylene & $\mathrm{ACN}$ & 2 & 152.2 & 3.22 \\
\hline Acenaphthene & $\mathrm{ACE}$ & 2 & 154.2 & 4.01 \\
\hline Fluorene & F0 & 2 & 166.2 & 4.21 \\
\hline C-1 fluorenes & F1 & 2 & 180.3 & 4.72 \\
\hline C-2 fluorenes & F2 & 2 & 194.3 & 5.20 \\
\hline C-3 fluorenes & F3 & 2 & 208.3 & 5.70 \\
\hline Dibenzothiophene & D0 & 3 & 184.2 & 4.53 \\
\hline C-1 dibenzothiophenes & D1 & 3 & 198.3 & 4.96 \\
\hline C-2 dibenzothiophenes & D2 & 3 & 212.3 & 5.42 \\
\hline C-3 dibenzothiophenes & D3 & 3 & 226.3 & 5.89 \\
\hline Phenanthrene & P0 & 3 & 178.2 & 4.57 \\
\hline C-1 phenanthrenes/anthracenes & P1 & 3 & 192.3 & 5.04 \\
\hline C-2 phenanthrenes/anthracenes & P2 & 3 & 206.3 & 5.46 \\
\hline C-3 phenanthrenes/anthracenes & P3 & 3 & 220.3 & 5.92 \\
\hline C-4 phenanthrenes/anthracenes & P4 & 3 & 234.3 & 6.32 \\
\hline Anthracene & ANT & 3 & 178.2 & 4.53 \\
\hline Fluoranthene & FLU & 3 & 202.3 & 5.08 \\
\hline Pyrene & PYR & 3 & 202.3 & 4.92 \\
\hline C-1 fluoranthenes/pyrenes & FP1 & 3 & 216.3 & 5.48 \\
\hline Benzo $[a]$ anthracene & BAA & 4 & 228.3 & 5.89 \\
\hline Chrysene & $\mathrm{C} 0$ & 4 & 228.3 & 5.71 \\
\hline C- 1 chrysenes & $\mathrm{C} 1$ & 4 & 242.3 & 6.14 \\
\hline $\mathrm{C}-2$ chrysenes & $\mathrm{C} 2$ & 4 & 256.3 & 6.43 \\
\hline C-3 chrysenes & $\mathrm{C} 3$ & 4 & 270.4 & 6.94 \\
\hline C-4 chrysenes & $\mathrm{C} 4$ & 4 & 284.4 & 7.36 \\
\hline Benzo $[b]$ fluoranthene & $\mathrm{BBF}$ & 6 & 252.3 & 6.27 \\
\hline Benzo $[k]$ fluoranthene & BKF & 6 & 252.3 & 6.29 \\
\hline Benzo[e]pyrene & BEP & 6 & 252.3 & 6.44 \\
\hline Benzo $[a]$ pyrene & BAP & 6 & 252.3 & 6.11 \\
\hline Perylene & PER & 5 & 252.3 & 6.44 \\
\hline Indeno $[1,2,3-c d]$ pyrene & ICP & 6 & 276.3 & 6.72 \\
\hline Dibenzo $[a, h]$ anthracene & DBA & 6 & 278.4 & 6.71 \\
\hline Benzo[ghi]perylene & BZP & 6 & 276.3 & 6.51 \\
\hline
\end{tabular}

${ }^{a}$ Deuterated surrogates were naphthalene- $d_{8}(1)$, acenaphthene- $d_{10}(2)$, phenanthrene- $d_{10}(3)$, chrysene$d_{12}(4)$, perylene- $d_{12}(5)$, and benzo $[a]$ pyrene- $d_{12}(6)$.

were expected, because hydrophobicity increases with molecular mass, a relationship often characterized by the log of the octanol-water partition coefficient $\left(\log K_{\text {ow }}\right)$ (Table 1$)$.

\section{MATERIALS AND METHODS}

\section{Laboratory tests}

Low-density polyethylene tubing (thickness, $\sim 98 \mu \mathrm{m}$ ) without additives (Brentwood Plastics, St. Louis, MO, USA) was cut into sections (length, $0.5 \mathrm{~m}$ ) and split longitudinally to form a single layer (width, $4.9 \mathrm{~cm}$ ). A final cleanup was necessary before deployment to ensure that membranes had not previously accumulated hydrocarbons from air; thus, PEMDs were immersed in pentane and alternately sonicated for $15 \mathrm{~min}$ and soaked for $30 \mathrm{~min}$ (two cycles). After a final 15-min sonic extraction, each PEMD was rinsed with clean pentane as it was removed from the sonic bath, stored in a hydrocarbon-free glass jar with a dichloromethane-rinsed aluminum foil lid, and frozen $\left(0^{\circ} \mathrm{C}\right)$ until deployment. The PEMDs deployed in these experiments were not weighed, but mass was estimated by weighing 10 additional, identically sized
PEMDs to the nearest milligram $(2.210 \pm 0.009 \mathrm{~g}$, mean \pm standard error).

To measure their capacity to accumulate hydrocarbons, PEMDs typically were exposed to water-accommodated fractions of oil for 26 or 52 days (range, 26-30 and 52-63 d, respectively). The shorter exposure times were within the range typical for SPMD field deployment (see, e.g., [3,6,7]). To provide a graded-dose series (five treatments including control) (Table 2), $22 \mathrm{~kg}$ of oiled or control rock were placed in each of nine polyvinyl chloride incubators (height, $60 \mathrm{~cm}$; diameter, $15 \mathrm{~cm}$ ) according to the methods of Heintz et al. [14]. Alaska North Slope crude oil was artificially weathered by heating for $12 \mathrm{~h}$ at $70^{\circ} \mathrm{C}$, then sprayed onto rock (middiameter, $5.4 \mathrm{~mm})$ at different dose levels $(0-3.8 \mathrm{~g} / \mathrm{kg}$ rock). Water flow was $1.6 \mathrm{~L} / \mathrm{min}$ and alternated between freshwater $(8 \mathrm{~h})$ and salt water $(4 \mathrm{~h})$ to simulate an intertidal environment representative of typical pink salmon spawning habitat. Water flowed $2 \mathrm{~d}$ before the start of the experiment to further weather the oil and remove any particulates. Approximately 2,700 pink salmon eggs were added to each incubator at the start of the study, and a day later, one PEMD was placed in the effluent 
Table 2. Dose levels in laboratory experiment 1 and resultant total polynuclear aromatic hydrocarbon (TPAH) concentrations in water, low-density polyethylene membrane devices (PEMDs), and pink salmon eggs ${ }^{\mathrm{a}}$

\begin{tabular}{|c|c|c|c|c|c|c|c|c|c|c|c|c|c|c|}
\hline \multirow{3}{*}{$\begin{array}{l}\text { Treat- } \\
\text { ment }\end{array}$} & \multirow{2}{*}{\multicolumn{5}{|c|}{ Aqueous TPAH $(\mu \mathrm{g} / \mathrm{L})$}} & \multirow[b]{3}{*}{$w$} & \multicolumn{4}{|c|}{ TPAH in PEMD (ng/g) } & \multicolumn{4}{|c|}{ TPAH in eggs $(\mathrm{ng} / \mathrm{g})$} \\
\hline & & & & & & & 1 to & 1 to & 27 to & 83 to & 0 to & 0 to & 0 to & 0 to \\
\hline & Initial & $28 \mathrm{~d}$ & $54 \mathrm{~d}$ & $75 \mathrm{~d}$ & $183 \mathrm{~d}$ & & $27 \mathrm{~d}$ & $53 \mathrm{~d}$ & $53 \mathrm{~d}$ & $146 \mathrm{~d}$ & $27 \mathrm{~d}$ & $53 \mathrm{~d}$ & $75 \mathrm{~d}$ & $183 \mathrm{~d}$ \\
\hline Control & 0.02 & 0.02 & 0.01 & 0.03 & 0.00 & $\mathrm{NE}$ & $280 \pm 53^{b}$ & 355 & NA & NA & 25 & 19 & 34 & 16 \\
\hline Trace & 0.66 & 0.01 & NA & 0.02 & NA & 5.0 & 4,560 & 4,670 & NA & NA & NA & NA & NA & NA \\
\hline Low & 0.94 & 0.03 & 0.02 & 0.03 & 0.00 & 1.4 & 7,450 & 6,680 & NA & NA & NA & 275 & 204 & 24 \\
\hline Mid & 3.70 & 0.19 & 0.30 & 0.11 & 0.02 & 0.6 & 26,900 & 24,200 & NA & NA & NA & $999 \pm 52^{\mathrm{c}}$ & 620 & 88 \\
\hline High & 16.52 & 0.62 & 0.16 & 0.09 & 0.07 & -1.2 & 118,000 & NA & 29,300 & 13,000 & 9,400 & 4,220 & 2,170 & 163 \\
\hline
\end{tabular}

${ }^{a}$ Sample times are days after experiment began. Mass is dry weight. NA $=$ not analyzed; NE $=$ not estimable; $w=$ the weathering coefficient in PEMDs on day 27. Except where standard error is reported, $n=1$.

${ }^{\mathrm{b}} n=2$.

${ }^{\mathrm{c}} n=4$.

of one randomly selected incubator per treatment. Initial aqueous TPAH concentrations ranged from 0.02 (control) to 16.52 $\mu \mathrm{g} / \mathrm{L}$ (Table 2). Hydrocarbon-free (dichloromethane-rinsed) tools were used to place and retrieve PEMDs, which were frozen in jars pending analysis. Water samples $(3.8 \mathrm{~L})$ and eggs $(\sim 10$ g wet wt) were collected at approximately the same time for hydrocarbon analysis (Table 2). Egg samples were frozen pending analysis. Additional PEMDs were placed in the high-oil treatment every $30 \mathrm{~d}$ to ensure reliable concentration factor estimates (Table 2). Total experimental duration was $184 \mathrm{~d}$.

To determine hydrocarbon retention, additional PEMDs were similarly exposed to water-accommodated fractions of oil, then transferred to clean water and observed for $40 \mathrm{~d}$. These PEMDs were exposed for $21 \mathrm{~d}$, transferred to clean water, and sampled after $0,10,20$, or $40 \mathrm{~d}$ of depuration. One PEMD was sampled at each observation time. Retention of PAH also was examined between 26 and $52 \mathrm{~d}$ in the uptake experiment, in which aqueous TPAH concentration for two of three independent data pairs was indistinguishable from the control level (in trace- and low-oil treatments) and was 5 to $8 \%$ of the initial aqueous concentration in the mid-oil treatment $(0.19-0.30 \mu \mathrm{g} / \mathrm{L})$, thus generally approximating depuration conditions.

\section{Field comparison of PEMD and SPMD samplers}

To compare performance, PEMDs and SPMDs were placed side by side in freshwater and intertidal areas. The SPMDs were purchased from Environmental Sampling Technologies (St. Joseph, MO, USA). Exposed surface area of the 2.6- $\times$ $100-\mathrm{cm}$ SPMDs was the same as that of the PEMDs. In freshwater (Auke Lake and surrounding streams, Juneau, AK, USA), two PEMDs paired with one SPMD were periodically deployed at four sites for 21- to 23-d periods (May 1999February 2000). Membranes were suspended in polyvinyl chloride pipe (diameter, 5-7.5 cm; length, $60 \mathrm{~cm}$ ) with open ends and two rows of $1.3-\mathrm{cm}$ holes spaced approximately 7.5 $\mathrm{cm}$ apart. In intertidal streams (Prince William Sound, AK, USA), four PEMDs and one SPMD were buried approximately 10 to $20 \mathrm{~cm}$ in the hyporheic zone below stream channels in each of four elevation zones [15] in each of six streams. Membranes were suspended centrally in perforated aluminum tubes (length, $69 \mathrm{~cm}$; diameter, $8.9 \mathrm{~cm}$; 3-mm holes spaced $4.8 \mathrm{~mm}$ on center) on stainless-steel clips fastened to nylon line. Tube ends were capped with aluminum window screen. Tubes, screens, associated hardware, and tools were washed with soap and water, dried, and rinsed with methylene chloride before use. Blank SPMD and PEMD samples were collected by first rigging membranes in a sampler, then retrieving them without placement in stream water. Membranes were recovered 45 to $56 \mathrm{~d}$ after placement and frozen until analysis.

\section{Analyses}

All hydrocarbon samples (PEMDs, SPMDs, tissue, and water) were extracted with organic solvent. The PEMDs were wiped to remove gross surface contamination, placed in centrifuge tubes, and spiked with six deuterated PAH standards (Table 3). Spike solvent (hexane) was allowed to evaporate, then the tubes were placed in a sonic bath and extracted in 80:20-ml pentane:dichloromethane for $130 \mathrm{~min}$. The sonicator was on for the first 20 min of each 50-min period. The PEMDs were rinsed with pentane as they were removed without delay after the final sonication; extracts were concentrated to 20 to $30 \mathrm{ml}$, dried with 2 to $4 \mathrm{~g}$ of sodium sulfate, concentrated to 1 to $2 \mathrm{ml}$ in hexane, and passed through 1.5-g silica gel columns. All SPMD dialyses were completed by Environmental Sampling Technologies. Dialyzate was spiked with six deuterated standards (Table 3), reduced in volume with Synder columns on a steam bath, purified by gel permeation highperformance liquid chromatography, and reduced in volume with hexane solvent transfer on a steam bath. Water samples were extracted with dichloromethane immediately after collection and spiked with $1 \mathrm{ml}$ of the six deuterated standards in acetone (Table 3) according to the methods of Short et al. [16]. Tissue samples were extracted with dichloromethane after addition of six internal standards (Table 3). Isolation and pu-

Table 3. Deuterated surrogate polynuclear aromatic hydrocarbon (PAH) standards and concentrations in spike used for water, polyethylene membrane devices (PEMDs), semipermeable membrane devices (SPMDs), and eggs ${ }^{\mathrm{a}}$

Spike concentration $(\mu \mathrm{g} / \mathrm{ml})$

\begin{tabular}{|c|c|c|}
\hline Water & $\begin{array}{c}\text { PEMDs, SPMDs, } \\
\text { and eggs }\end{array}$ & Surrogate \\
\hline 1.0 & 2.5 & Naphthalene- $d_{8}$ \\
\hline 1.0 & 2.5 & Acenaphthene- $d_{10}$ \\
\hline 0.8 & 2.0 & Phenanthrene- $\mathrm{d}_{10}$ \\
\hline 0.8 & 2.0 & Chrysene- $\mathrm{d}_{12}$ \\
\hline 1.0 & 2.5 & Perylene- $\mathrm{d}_{12}$ \\
\hline 1.0 & 2.5 & Benzo $[a]$ pyrene- $\mathrm{d}_{12}$ \\
\hline
\end{tabular}

${ }^{a}$ Spike volumes were $500 \mu \mathrm{L}$ for water, SPMD, and eggs and 200 $\mu \mathrm{L}$ for PEMDs. Spike solvent was acetone for water and hexane for PEMDs, SPMDs, and eggs. 
rification of calibrated and uncalibrated compounds in tissue samples was completed by silica gel/alumina column chromatography followed by size-exclusion high-performance liquid chromatography and fractionation [16,17]. All extracts were spiked with an internal standard (hexamethyl benzene) and frozen pending analysis.

Extracts were analyzed by gas chromatography equipped with a mass-selective detector, and PAH concentrations were determined by the internal standard method [16]. Experimentally determined method detection limits generally were $1 \mathrm{ng} /$ $\mathrm{g}$ for tissue, 1 to $8 \mathrm{ng} / \mathrm{L}$ in water, and 0.18 to $3.94 \mathrm{ng} / \mathrm{g}$ in PEMDs and SPMDs; concentrations less than the method detection limits were considered to be equivalent to zero and are not reported. The accuracy of the hydrocarbon analyses was approximately $\pm 15 \%$ based on comparison with National Institute of Standards and Technology values, and precision expressed as coefficient of variation usually was less than approximately $20 \%$, depending on the PAH. Samples with questionable internal standard recoveries $(<25 \%$ or $>150 \%)$ were excluded from analysis or accepted only as specifically indicated and when results could be independently corroborated by other data. Internal standard recoveries in PEMDs increased from naphthalenes $(54 \% \pm 2 \%)$ to phenanthrenes $(83 \% \pm 1 \%)$ and declined slightly toward higher-molecular-mass PAH (70\% $\pm 2 \%$ for benzo[ $[a]$ pyrene), except that peryelene recovery was $80 \% \pm 2 \%$.

A first-order loss-rate kinetic weathering model was used to determine if PAH composition in PEMDs and eggs was consistent with composition in source oil and to summarize PAH composition [18]. Oil composition is summarized by a weathering index $(w)$; values range from less than zero (composition dominated by lower-molecular-wt PAH) to greater than eight (composition dominated by higher-molecular-wt PAH).

Concentrations of TPAH were calculated by summing concentrations of individual PAH (Table 1). The time when TPAH concentrations in eggs was at maximum was estimated for each treatment using a first-order kinetic model that accounted for uptake from water and declining aqueous TPAH concentrations [14]. Relative PAH concentrations were calculated as the ratio of PAH to TPAH. Concentration factors in PEMDs were estimated by dividing TPAH concentration (ng/g) by geometric mean aqueous TPAH concentrations $(\mu \mathrm{g} / \mathrm{L})$. Final aqueous TPAH concentrations were estimated by least-squares regression when PEMDs were collected more than $1 \mathrm{~d}$ before measurement of corresponding aqueous TPAH concentration. Concentration factors were similarly estimated for eggs.

Regression models considered when relating TPAH in matrices (water, PEMD, SPMD, and tissue) to each other were ladder of powers ( $x$-transformations, $x^{3}$ to $-1 / x^{3}$ ), exponential, and power. Because ordinary least-squares regressions often are not suitable when both $x$ - and $y$-terms are measured with error, the major-axis method [19] was used to estimate slopes when comparing PEMD and SPMD performance.

Rates of TPAH decline from PEMDs, tissue, and water were regressed (exponential models), and rate constants $(k)$ were compared. To scale them equally, concentrations in each data set were divided by the initial concentration in that set. Initial concentrations began on day 0 for all PEMD and aqueous data and on day 53 for pink salmon eggs. Relative declines across oil treatment in tissue and water were similar; thus, all oil treatments were used as replicates in this analysis. The TPAH concentrations in tissue were normalized to those on day 53, because this was the first time all treatments were analyzed. Normalized results were consistent with those in the high-oil treatment when normalized to TPAH concentration on day 15 , the earliest tissue sample. Two-compartment exponential decay was necessary to adequately model TPAH loss from water. To ensure that regressions were meaningful, we adopted the approach that the $F$-ratio of a regression $\left(F_{\mathrm{o}}\right)$ should exceed the usual significance ratio $\left(F_{\mathrm{c}}\right)$ by a multiple of at least fourfold [20]. Instantaneous rate estimates, $\left(\ln \left(C_{t} / C_{0}\right)\right) / t$, where $C_{t}=$ concentration at time $t$ and $C_{0}=$ initial concentration, were calculated when too few data were available for regression analysis.

Concentration factors of individual PAH by PEMDs and eggs were related to molecular mass by exponential regression. The shortest possible observation period was used for these calculations, $26 \mathrm{~d}$ for PEMDs (all oil treatments) and $15 \mathrm{~d}$ for eggs (high-oil treatment only). Concentration factors for each analyte were estimated by dividing the observed concentration $(\mathrm{ng} / \mathrm{g})$ by the geometric mean aqueous concentration $(\mu \mathrm{g} / \mathrm{L})$ observed during exposure intervals.

Retention of individual PAH by PEMDs and eggs was examined as a function of molecular mass. Two PEMD data sets were examined, paired 26- and 52-d data (in which aqueous TPAH levels had either fallen to control levels or were near them) (Table 2) and clean-water depuration data. In eggs, paired 53- and 75-d data (all treatments) and 27- and 53-d data (high-oil treatment only) were examined. The concentration of each PAH analyte was divided by that of the corresponding analyte in earlier samples (or mean analyte concentration when replicated) and then multiplied by 100 to express the result as a percentage. Data for which ratios were not calculable were omitted (initial analyte concentrations $<$ method detection limits). Percentage retention was regressed (linear) against molecular mass by treatment or by depuration time. Analysis of PEMDs placed in clean water was restricted to three- to fivering PAH; all PAHs were included in other PEMD and egg analyses. To compare slopes, data were further examined with analysis of covariance after removal of outliers.

To compare PAH composition in PEMD and SPMD samplers, differences in relative $\mathrm{PAH}$ concentrations in each device were calculated. Comparison of relative PAH composition was restricted to locations with evidence of hydrocarbons (several Auke Lake sites and portions of two Prince William Sound streams). Data in which PAH/TPAH were zero in both samplers were not included in estimates of mean differences. Also, C3phenanthrenes were not included in samples from Prince William Sound, because a broad competing peak (probably octadecanoic acid or its methyl esters) precluded quantification in SPMDs. Single SPMD concentration estimates at each site and time were subtracted from mean estimates $(1 \leq n \leq 4)$ in paired PEMDs. A more complex, multivariate analysis of variance designed to compare composition with normalized PAH vectors [21] failed, because the data set was not large enough.

\section{RESULTS}

TPAH uptake by PEMDs and eggs

Concentrations of TPAH in PEMDs and eggs were all closely correlated with initial concentrations in water whenever measured $\left(0.933 \leq r^{2} \leq 1.000\right)$. Initial aqueous TPAH exposure concentrations ranged from $0.02 \mu \mathrm{g} / \mathrm{L}$ (controls) to 17 $\mu \mathrm{g} / \mathrm{L}$ (high treatment) and declined rapidly in oil treatments (Table 2). The TPAH concentrations in PEMDs deployed $1 \mathrm{~d}$ 
after dosing began and soaked for $26 \mathrm{~d}$ were linearly correlated with initial aqueous TPAH concentrations $\left(r^{2}>0.999, n=\right.$ $6)$, as were those soaked for $52 \mathrm{~d}\left(r^{2}>0.999, n=4\right)$, demonstrating that PEMDs were not saturated at aqueous TPAH concentrations of $17 \mu \mathrm{g} / \mathrm{L}$ of less. Concentrations of TPAH in eggs were correlated with initial aqueous TPAH concentrations after 53-, 75-, and 183-d exposures $\left(0.991 \leq r^{2} \leq 1.000 ; 4 \leq\right.$ $n \leq 8)$. Maximum TPAH concentrations in PEMDs $(118,000$ $\mathrm{ng} / \mathrm{g}$ dry wt) exceeded those in eggs $(10,800 \mathrm{ng} / \mathrm{g}$ dry wt) by an order of magnitude.

The capacity of PEMDs to accumulate TPAH from water was large. Estimated concentration factors for PEMDs, which typically were complicated by rapidly changing aqueous TPAH concentrations, ranged from a minimum of $7.1 \times 10^{3}$ to a maximum of $1.6 \times 10^{5}$, depending on the calculation method. Minimal concentration factor estimates were 7,150 $\pm 160(n$ $=7$ ) when initial aqueous TPAH was the divisor. This likely underestimates the actual concentration factor, because aqueous concentrations dropped rapidly. An intermediate estimate of $67,000 \pm 10,000(n=7)$ was obtained using geometric mean aqueous TPAH concentrations. The highest and, possibly, most accurate concentration factor estimate $\left(1.6 \times 10^{5}\right)$ was based on a single 63-d deployment in the high-oil treatment in which bounding aqueous TPAH concentrations were nearly constant $(0.09$ and $0.07 \mu \mathrm{g} / \mathrm{L}$ on days 75 and 183 , respectively) (Table 2).

Total PAH concentration factors in pink salmon eggs were smaller than in PEMDs. Calculation of concentration factors in eggs was complicated by declining TPAH concentrations in both water and tissue and by sample timing. The maximum observed TPAH accumulation in eggs was $10,800 \mathrm{ng} / \mathrm{g}$ dry weight on day 15 (high-oil treatment), shortly before the estimated maximum accumulation of $11,000 \mathrm{ng} / \mathrm{g}$ dry weight on day 18 in this treatment. Most tissue was not analyzed until day 53; thus, maximum uptake capacity probably is underestimated. For example, TPAH concentration in high-oil treatment eggs was $4,220 \mathrm{ng} / \mathrm{g}$ dry weight on day $53,39 \%$ of that observed on day 15 . Under these conditions, the mean concentration factor for eggs was $2,900 \pm 340(n=4$; day 53; based on geometric mean aqueous concentration), roughly 20fold less than in PEMDs. When expressed per dry weight of lipid, the concentration factor for eggs was 9,200 $\pm 1,100$ (approximately sevenfold less than in PEMDs), a measure more directly comparable to PEMDs (which are functionally a very large lipid), because most PAH in eggs likely is associated with lipid.

\section{Uptake of specific PAH by PEMDs and eggs}

Accumulation of individual PAH in PEMDs and eggs increased exponentially as molecular mass increased $\left(0.76 \leq r^{2}\right.$ $\left.\leq 0.82, p<0.001,16 \leq F_{\mathrm{o}} / F_{\mathrm{c}} \leq 103\right)$, and concentration factors consistently increased with alkyl-substitution within each homologous family (Fig. 1). However, the slope for PEMDs was significantly greater than for eggs $\left(p_{\text {ANCOVA }}<\right.$ 0.001, where ANCOVA is analysis of covariance). The slope did not change when uptake in eggs was based on a wet- or dry-weight basis (instead of lipid), but the position of the curve was displaced downward.

\section{PAH composition in water, PEMDs, and eggs}

The PAH composition in exposure water, PEMDs, and pink salmon eggs was related to that in the source oil (Alaska North Slope crude) but differed in specific details (Fig. 2). Naph-

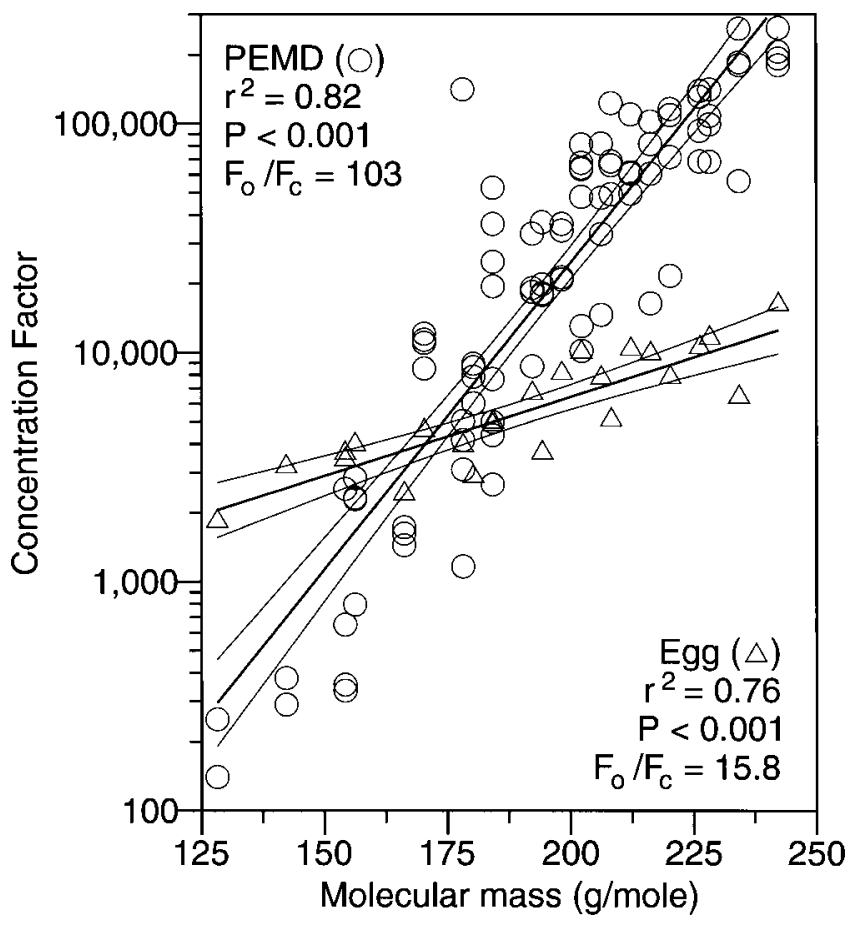

Fig. 1. Concentration factors of polynuclear aromatic hydrocarbons in low-density polyethylene membrane devices (PEMDs) and pink salmon eggs as functions of molecular mass. Illustrated are exponential regressions with $95 \%$ confidence bands and associated statistics; $F_{\mathrm{o}} / F_{\mathrm{c}}$ is the ratio between the observed $F$ value and the critical $F$ value.

thalenes, fluorenes, dibenzothiophenes, and phenanthrenes were consistently present in all three media. Specific PAH composition in each medium differed from that in the source oil for several reasons. In water, enrichment of smaller-molecular-weight PAH (e.g., naphthalene) was evident, because these molecules dissolve more readily from the contaminant oil film (compare Fig. 2b to 2a). Conversely, larger-molecularweight PAH (chrysenes) were underrepresented in water and often near or less than detection limits; thus, verification of source oil was not possible with a first-order loss-rate kinetic weathering model [18]. In PEMDs, PAH composition was more characteristic of weathered oil, because proportionately fewer lower-molecular-weight PAHs were accumulated or retained (Fig. 2d). Percentages of naphthalenes in PEMDs were always less than bounding percentages in water, and percentages of phenanthrenes were usually greater (e.g., compare Fig. $2 \mathrm{~d}$ to $2 \mathrm{~b}$ and $2 \mathrm{c}$ ). The $\mathrm{PAH}$ was more easily detectable in PEMDs than in water, because it was concentrated by the plastic and the source of oil was verifiable in all oil-exposed PEMDs [18]. In pink salmon eggs, naphthalenes were the dominant PAH accumulated, and composition was most similar to initial aqueous PAH composition (compare Fig. 2e to 2b). Percentages of naphthalenes tended to increase with time in eggs, and the source oil typically could not be verified [18]. This was because one or more chrysene homologues were less than the method detection limits.

\section{Retention of TPAH by PEMDs and eggs}

The estimated TPAH retention in PEMDs placed in clean water was $78 \%$ in $40 \mathrm{~d}$, and the instantaneous loss rate was -0.006 per $\mathrm{d}$. Interpretation was complicated by poor recovery of two-ring PAH in other depuration samples. However, loss 


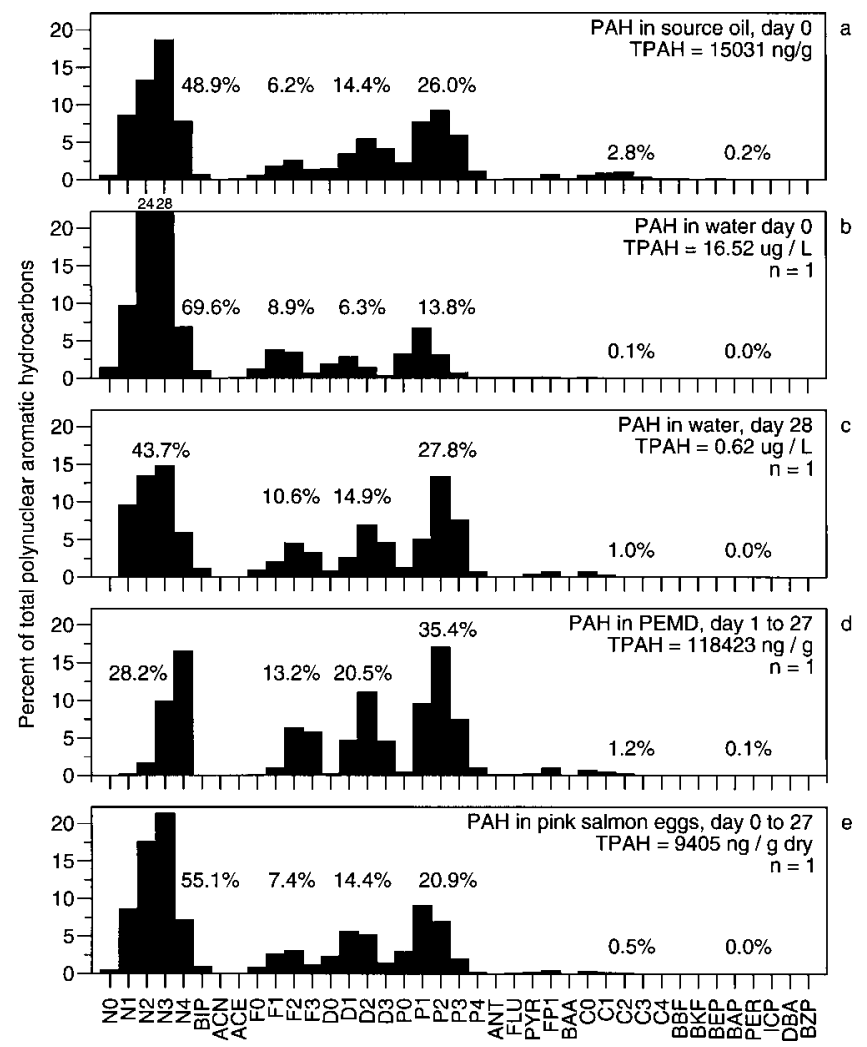

Fig. 2. Relative polynuclear aromatic hydrocarbon (PAH) composition in source oil, water, low-density polyethylene devices (PEMDs), and pink salmon eggs. Observation times and total PAH (TPAH) concentration are noted in each panel. See Table 1 for explanation of the $x$ axis and for acronym definitions. Percentages (of TPAH) in each panel indicate relative quantities of naphthalenes (N0-N4), fluorenes (F0F3), dibenzothiophenes (D0-D3), phenanthrenes (P0-P4), chrysenes $(\mathrm{C} 0-\mathrm{C} 4)$, and five-ring PAHs (BBF to BZP).

of TPAH from PEMDs after 10 and $20 \mathrm{~d}$ was consistent with the 40-d estimate (Fig. 3), indicating that mathematical correction for poor recovery in these samples was reasonable. To further assess the accuracy of the clean-water depuration data, TPAH loss rates were examined in three paired 26- and 52-d samples in which aqueous concentrations were negligible (trace- and low-oil treatments) or low (mid-oil treatment) (Table 2). Estimated instantaneous TPAH loss rates in these paired samples ranged from 0.001 to -0.004 . That no loss was evident where $w$ was greatest (trace-oil treatment) (Table 2) is consistent with better retention of higher-molecular-weight PAH than lower-molecular-weight PAH by PEMDs, as demonstrated in the next section. The estimated rate of loss between 26 and $52 \mathrm{~d}$ where initial TPAH concentration was highest and mean $w$ was the lowest (mid-oil treatment) likely was slowed by residual aqueous PAH (5-8\% remaining between 26 and 52 d).

Loss of TPAH from PEMDs in clean water $(k=-0.006$ $\pm 0.001)$ was slower than loss from pink salmon eggs maintained in declining aqueous TPAH concentrations $(k=-0.021$ $\pm 0.002)$ and much slower than loss from water $\left(k_{1}=-0.216\right.$ \pm 0.032 ) (Fig. 3). Although eggs were never removed from treatment water, tissue concentrations peaked between approximately 18 and $22 \mathrm{~d}$ [14] and then declined, well before depuration modeling began at day 53 (Fig. 3).

\section{Retention of individual PAH by PEMDs and eggs}

The PEMDs retained higher-molecular-mass PAH better than they did lower-molecular-mass PAH (Fig. 4a and b). The

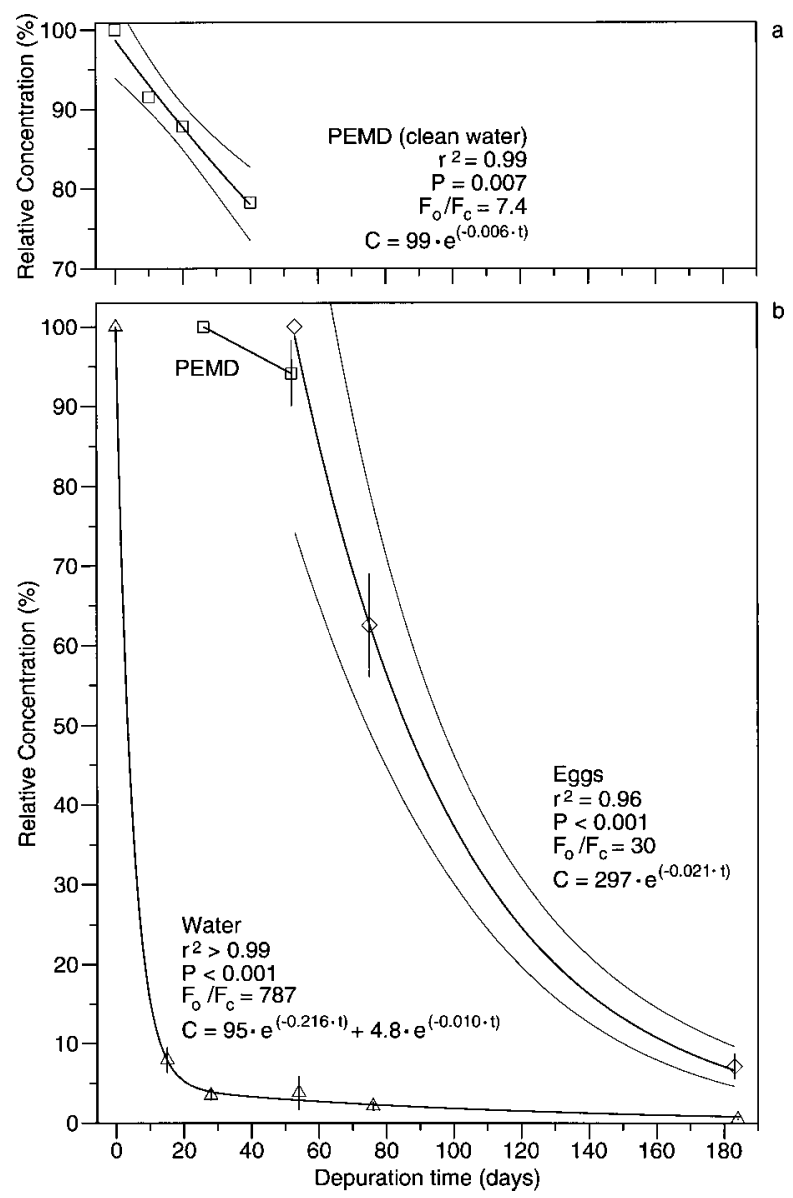

Fig. 3. Relative total polynuclear aromatic hydrocarbon (PAH) concentrations $(C)$ in low-density polyethylene membrane devices (PEMDs), pink salmon eggs, and water as exponential functions of depuration time $(t)$. Some PEMDs depurated in clean water (a) $(n=$ 1 for each plotted point). Other PEMDs and pink salmon eggs (means \pm standard error) were maintained in falling aqueous total PAH concentrations (b). Where present, bounding curves are $95 \%$ confidence bands; $F_{\mathrm{o}} / F_{\mathrm{c}}$ is the ratio between the observed $F$ value and the critical $F$ value.

relationship between PAH retention and molecular mass was clear in all paired treatments after removal of outliers $(0.61$ $\leq r^{2} \leq 0.86, p<0.001,9.2 \leq F_{\mathrm{o}} / F_{\mathrm{c}} \leq 41$ ) (Fig. 4a). Slopes ranged from 0.5 to $1.2 \% \mathrm{~mol} / \mathrm{g}$ and was significantly greater in the mid-oil treatment than in the lower two treatments, possibly because mid-oil aqueous TPAH concentrations were greater than in controls between days 26 and 52 and relatively more high-molecular-mass PAH was present in the water than low-molecular-mass PAH. However, estimated PAH retention in PEMDs in which molecular mass was greater than approximately $200 \mathrm{~g} / \mathrm{mol}$ generally was more than $100 \%$, suggesting either measurement imprecision or that some larger PAH may have continued to pass through the water undetected and accumulate on all of these PEMDs between days 26 and 52 . Some clean-water retention estimates also exceeded $100 \%$, also suggesting measurement imprecision (Fig. 4b).

The PEMDs also retained higher-molecular-mass PAH better in clean-water depuration tests (Fig. 4b). Only three- to five-ring PAHs were examined in this analysis; two-ring $\mathrm{PAH}$ was not included because of measurement error. Retention of two analytes, phenanthrene and fluoranthene, was consistently greater than $200 \%$ (theoretically impossible), and these results also were rejected as a measurement error. Retention of PAH 


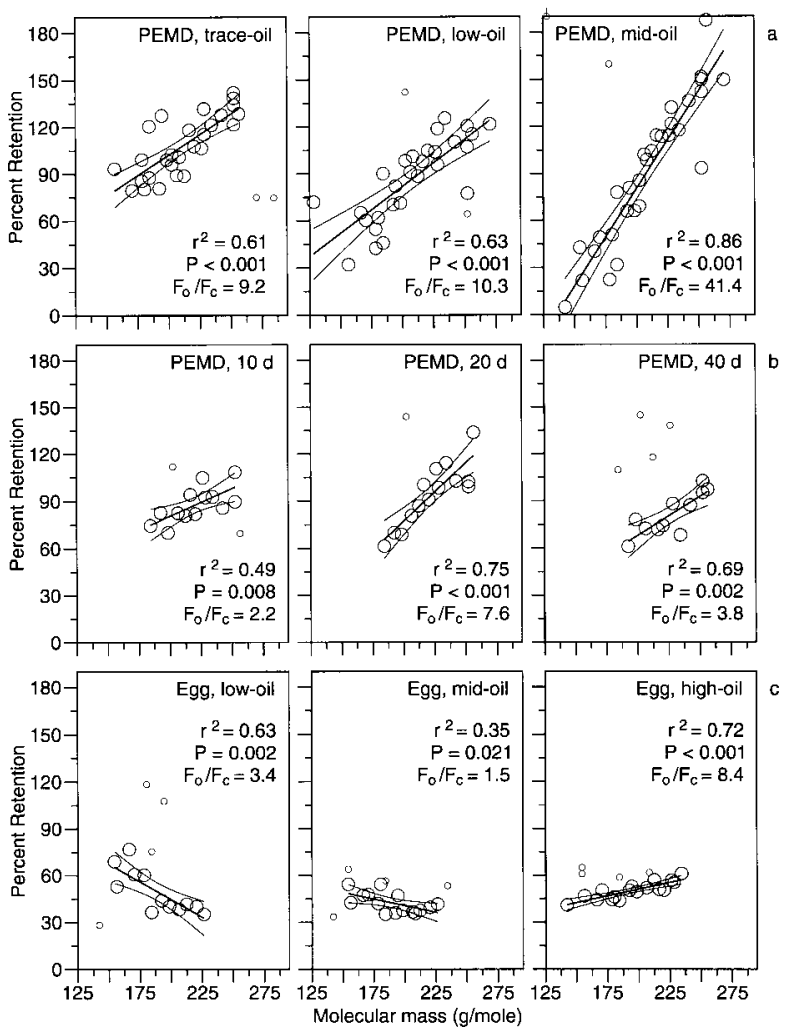

Fig. 4. Retention of polynuclear aromatic hydrocarbons (PAH) in lowdensity polyethylene membrane devices (PEMDs) and pink salmon eggs as functions of molecular mass. (a) Estimates compare PEMD retention between days 26 and 52 maintained in water where aqueous total PAH concentrations were at or rapidly approaching background levels. (b) Estimates were completed in clean water after 10, 20, and $40 \mathrm{~d}$ of depuration and include three- to five-ring PAH only. (c) Retention estimates in eggs were completed between days 53 and 75 where aqueous total PAH concentrations were at or near background levels. All illustrated regressions are linear with $95 \%$ confidence bands. Small symbols indicate outliers identified by regression analysis and not included in final analyses.

in all three observations increased significantly as molecular mass increased $\left(0.49 \leq r^{2} \leq 0.75,0.001<p \leq 0.008,2.2 \leq\right.$ $\left.F_{\mathrm{o}} / F_{\mathrm{c}} \leq 7.6\right)$ (Fig. $4 \mathrm{~b}$ ). Clean-water depuration results were consistent with those in paired samples, and slopes were indistinguishable from those in paired tests in which aqueous $\mathrm{TPAH}$ concentrations were at background levels $\left(p_{\text {ANCOVA }}=\right.$ 0.324),

In pink salmon eggs, evidence that $\mathrm{PAH}$ retention was related to molecular mass was inconsistent (Fig. 4c). Retention of PAH between days 53 and 75 was unrelated to mass in one treatment (extreme-oil, $r^{2}=0.09, p=0.221, F_{\mathrm{o}} / F_{\mathrm{c}}=0.4$ ) declined significantly in two treatments $\left(0.35 \leq r^{2} \leq 0.63\right.$, $\left.0.002 \leq p \leq 0.021,1.5 \leq F_{\mathrm{o}} / F_{\mathrm{c}} \leq 3.4\right)$ and increased significantly in the remaining treatment (high-oil, $r^{2}=0.72, p<$ $0.001, F_{\mathrm{o}} / F_{\mathrm{c}}=8.4$ ) (Fig. 4c). Retention of PAH also may have increased with molecular mass in an earlier observation of the high-oil treatment, but correlation was poor (days 27-53, $r^{2}$ $\left.=0.27, p=0.015, F_{\mathrm{o}} / F_{\mathrm{c}}=1.6\right)$. The inconsistent relationship between retention and molecular mass in eggs was unlike the situation in PEMDs, suggesting that mechanisms influencing PAH loss were different.

\section{PEMD and SPMD comparison}

Composition of PAH accumulated by PEMDs and SPMDs in side-by-side field tests was similar (see, e.g., Fig. 5). Dif-

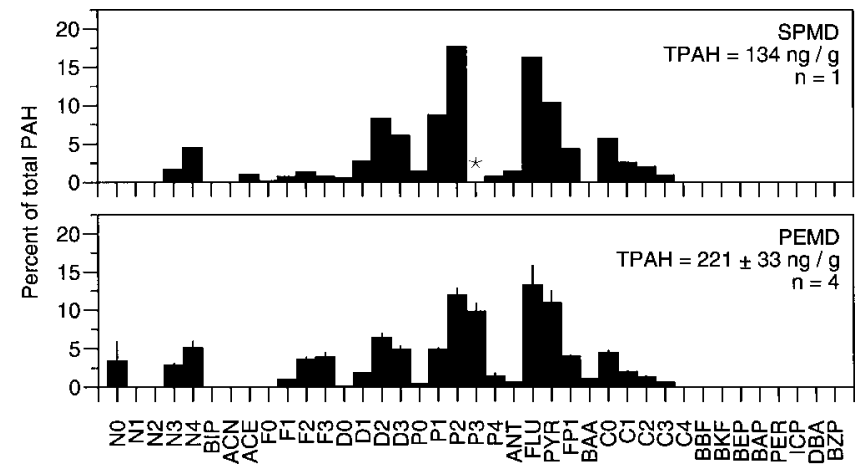

Fig. 5. Comparison of polynuclear aromatic hydrocarbon (PAH) composition \pm standard error in low-density polyethylene membrane devices (PEMDs) and semipermeable membrane devices (SPMDs) deployed together at 1.8 to $2.4 \mathrm{~m}$ above mean lower low water in Sleepy Creek, Prince William Sound (AK, USA). Total PAH (TPAH) concentrations are noted in each panel. See Table 1 for explanation of the $x$-axis. An asterisk indicates that C3-naphthalenes were present in the SPMD sample but could not be quantified because of the presence of competing ions associated with triolein or its derivatives.

ferences between relative PAH concentrations in PEMDs and SPMDs (from Prince William Sound and Auke Lake) averaged $-0.1 \% \pm 0.3 \%(n=336)$ and in nearly all cases were within $\pm 5 \%$.

The capacity of PEMDs and SPMDs to accumulate PAH also was approximately the same, as expected, because the devices had equal surface areas and probable exposure concentrations were low. The TPAH concentrations in PEMDs and SPMDs (range, 2-1,430 ng/g) were strongly correlated in samples from a freshwater lake $\left(r^{2}=0.992, p<0.001, n=\right.$ 12). Major-axis slope estimates were 0.999 and 1.001 , indicating that these devices functioned similarly in the lake. Accumulation of TPAH in PEMDs and SPMDs (range, 20-221 $\mathrm{ng} / \mathrm{g}$ ) also was similar in intertidal streams (major-axis slope estimates were 0.936 and 1.068). Correlation was poorer within this smaller concentration range $\left(r^{2}=0.371, p=0.002, n\right.$ $=23$ ). Clearly, PEMDs performed at least as well as SPMDs within observed TPAH ranges as assessed by accumulation capacity and similarity in PAH composition.

\section{DISCUSSION}

These experiments demonstrate that PEMDs are reliable passive sampling devices capable of accumulating PAH from water, a conclusion also reached by others [8,9,22]. Concentrations of TPAH accumulated by PEMDs were highly correlated with concentrations in oil-contaminated water, and no evidence was observed for saturation at aqueous concentrations less than $17 \mu \mathrm{g} / \mathrm{L}$. Hydrocarbons were highly concentrated in PEMDs, improving the detection of PAH only present at low levels in water (e.g., chrysenes). Composition of PAH accumulated in PEMDs was consistent with source oil, and although PAH detected in PEMDs was consistently more weathered than in source water (i.e., relatively fewer naphthalenes and more phenanthrenes), composition varied with that in water and was highly similar to accumulations in commercially available SPMDs. The PEMDs maintained in clean water retained most accumulated PAH (78\% in $40 \mathrm{~d})$. The PEMD and SPMD samplers deployed in a field setting clearly provided the same information: TPAH concentrations were correlated, and differences in relative PAH composition averaged zero. Thus, a simple plastic membrane can be conve- 
niently used for environmental monitoring, and the lipophilic reservoir present in SPMDs is not always necessary.

Our approach to environmental monitoring has been to simplify the data collection and analysis as much as practical, and we have demonstrated that PEMDs perform well as low-level hydrocarbon monitors in aquatic environments. Unlike directly processed water samples, passive membrane samplers provide time-integrated, concentrated samples, thereby increasing the likelihood of detecting low-level or intermittent contaminants [7]. Sampling costs also may be lowered, because frequent collection, processing, and extraction of large water samples may be required to achieve the same results [23]. The PEMDs share many of the same attributes of SPMDs, which have been accepted for the monitoring of lipophilic contaminants since their introduction [1] more than a decade ago (see, e.g., [24,25]. Although the lipophilic central reservoir in SPMDs more closely mimics transfer of hydrocarbons across biological membranes and is capable of storing high hydrocarbon concentrations in the reservoir (theoretically, $\sim 3 \times 10^{4}$ for hydrocarbons with $\log K_{\text {ow }}>5.5$ [13]), PEMD uptake capacity is also high (roughly $10^{4}$ - to $10^{5}$-fold aqueous TPAH concentrations). Estimated capacity of PEMDs to accumulate PAH also is similar to pesticide uptake $\left(5.5 \times 10^{4}\right.$ times $)$ by similar devices [13] and in mussels ( $2 \times 10^{5}$ in Mytilus edulis [26]). Our experience indicates that PEMDs provide reliable data at low environmental TPAH concentrations, a conclusion also reached for pesticides and polychlorinated biphenyls (PCBs) by Hofelt [8].

The difference in surface to volume ratios in PEMDs and eggs likely was a primary factor in the kinetically controlled uptake differences between them. The surface to volume ratio in PEMDs (227) was much greater than that in pink salmon eggs (0.87, with an average egg diameter of $6.9 \mathrm{~mm}$ [27]), explaining in part why more PAH accumulated in PEMDs per unit mass than in eggs ( $\sim 20$ times). The importance of surfacevolume relationships also is evident in an experiment by Luellen [9], in which PEMDs with twice the surface area of SPMDs accumulated PAH more rapidly.

Differences in rates of $\mathrm{PAH}$ accumulation and loss in PEMDs explain why the PAH composition in PEMDs was different than that in water. Our results indicate that $\mathrm{PAH}$ uptake increases exponentially with molecular mass (and with $\log K_{\text {ow }}$, because it is linearly related to molecular mass) (Table 1). Furthermore, higher-mass $\mathrm{PAH}$ are preferentially retained by PEMDs in clean water. This selective sampling causes PAH composition in PEMDs to differ from that in water, yet the source of oil remained identifiable in PEMDs, perhaps in part because smaller PAH preferentially accumulate in water. Sizerelated (and, hence, lipophilic) differences in PAH uptake and retention are consistent with first-order kinetics [18], and dissolution processes probably are primarily responsible for these differences. The sampling efficiency of PEMDs may decline for organic hydrocarbons in which $\log K_{\text {ow }}$ is greater than approximately 5.5 [9]. However, in our uptake study, few PAHs with $\log K_{\text {ow }}$ of 6 or greater were present $(9 \%)$, and none with $\log K_{\mathrm{ow}}$ of 6.5 of greater was present. Thus, we did not observe this decline.

The PEMDs lost TPAH slowly in clean water (22\% in 40 d). We conclude the rate of PAH loss is slow enough that PEMD membranes are valuable as passive sampling devices, corroborated by high TPAH retention (90-100\%) in PEMDs in water where TPAH concentrations had declined to background or near-background levels.
The PAH composition in PEMDs was very different than that in pink salmon eggs, indicating that PEMD data cannot simply be substituted for direct measures of biologically accumulated hydrocarbons in all cases. These differences were not surprising, because uptake and depuration kinetics likely differ between passive samplers and living organisms. The latter have complex structures and active cellular processes, including the ability to metabolize and actively export hydrocarbons [5]. Greater impedance of larger PAH by the chorion or other intervening membranes may explain differences in accumulation bias between PEMDs and pink salmon eggs (Fig. 1). In small planktonic fish larvae (with no chorions), accumulation bias toward larger PAH [28] was approximately the same as in our PEMDs and substantially greater than in salmon eggs.

The complexity of living systems can make identification of source contamination more difficult than in passive samplers. Uptake and retention of PAH in organisms depends on a variety of factors, such as species differences, life stage, physiological condition, lipid composition, temperature, and salinity. Correlation has been reported between uptake of hydrocarbons by SPMDs and biological species of interest-for example, organochloride pesticides and PCBs in mussels $(M$. edulis [6]), organochlorides in freshwater clams (Corbicula fluminea [2]), and PCBs in brown trout (Salmo trutta [29]). However, PCB conger distribution in freshwater clams was different than in SPMDs, as were distributions of ionizable chlorinated phenolic compounds in lake mussels (Anodonta piscinalis [2]). Clearly, neither PEMD nor SPMD data can simply replace direct measurement in a particular species without detailed parallel study.

That PAH composition in pink salmon eggs became increasingly naphthalene dominated may have been caused by the preferential metabolism of larger PAH, which is consistent with the conclusion by Echols et al. [3] that differences in contaminant profiles between channel catfish (Ictalurus punctatus) and SPMDs likely were caused by metabolism and depuration of certain PCB congeners by the fish. For example, cytochrome P4501A is induced by $\mathrm{PAH}$ with three or more rings but may not be induced by PAH with two rings [30]. Others have reported that naphthalenes induce cytochrome $\mathrm{P} 4501 \mathrm{~A}$ and ethoxyresorufin- $O$-deethylase activity, but less so than benzo[a]pyrene [31]. Cytochrome P4501A activity was elevated in oil-exposed embryos throughout the time that PAH retention was studied (unpublished data), and these maturing embryos had active circulatory systems, increasing the probability that metabolic activity influenced PAH composition.

The PEMDs reliably accumulate and retain two- to fivering $\mathrm{PAH}$ and can be used to assess environmental hot spots, particularly where exposures may be pulsed or intermittent. Because PEMDs integrate exposure over time, accumulated PAH concentrations are difficult to relate directly to waterquality standards. Variables previously identified for SPMD interpretation, including mean exposure temperature, extent of biofouling on samplers, and knowledge of effective daily sampling rates for contaminants of interest [7] are needed for informed back-calculation of aqueous hydrocarbon concentrations. Nonequilibrium conditions further complicate estimation of aqueous hydrocarbon concentrations. However, PEMDs can be used to distinguish areas with relatively higher PAH concentrations from those with lower concentrations. The PEMDs can potentially be used to identify source contami- 
nation, but analysis of time-integrated samples with multiple exposure possibilities will be challenging.

\section{CONCLUSION}

We conclude that PEMDs reliably sample lipophilic hydrocarbons from aquatic environments and provide a method for monitoring low-level, sporadic hydrocarbon levels. Data provided by PEMDs under these conditions are comparable to SPMD data. Loss of accumulated PAH is slow; thus, PEMDs can reliably capture sporadic or fluctuating events. Composition of PAH accumulated by PEMDs can be used to identify hydrocarbon sources in situations not complicated by multiple sources. We recommend PEMDs as cost-effective, simple tools for environmental monitoring.

Acknowledgement-We thank Adam Moles and two anonymous reviewers for their helpful suggestions. The research described in the present paper was supported by the Exxon Valdez. Oil Spill Trustee Council. However, the findings and conclusions presented by the authors are their own and do not necessarily reflect the view or position of the Trustee Council.

\section{REFERENCES}

1. Huckins JN, Tubergen MW, Manuweera GK. 1990. Semipermeable membrane devices containing model lipid: A new approach to monitoring the bioavailability of lipophilic contaminants and estimating their bioconcentration potential. Chemosphere 20:533-552.

2. Prest HF, Huckins JN, Petty JD, Herve S, Paasivirta J, Heinonen P. 1995. A survey of recent results in passive sampling of water and air by semipermeable membrane devices. Mar Pollut Bull 31:306-312.

3. Echols KR, Gale RW, Schwartz TR, Huckins JN, Williams LL, Meadows JC, Morse D, Petty JD, Orazio CE, Tillitt DE. 2000. Comparing polychlorinated biphenyl concentrations and patterns in the Saginaw River using sediment, caged fish, and semipermeable membrane devices. Environ Sci Technol 34:4095-4102.

4. Livingstone DR, Pipe RK. 1992. Mussels and environmental contaminants: Molecular and cellular aspects. In Gosling E, ed, The Mussel Mytilus: Ecology, Physiology, Genetics and Culture. Elsevier, New York, NY, USA, pp 425-464.

5. Vrolijk NH, Targett NM, Wooding BR, Stegeman JJ. 1994. Toxicological and ecological implications of biotransformation enzymes in the tropical teleost Chaetodon capistratus. Mar Biol 119:151-158.

6. Hofelt CS, Shea D. 1997. Accumulation of organochlorine pesticides and PCBs by semipermeable membrane devices and $M y$ tilus edulis in New Bedford Harbor. Environ Sci Technol 31: 154-159.

7. Huckins JN, Petty JD, Lebo JA, Orazio CE, Prest HF, Tillitt DE, Ellis GS, Johnson BT, Manuweera GK. 1996. Semipermeable membrane devices (SPMDs) for the concentration and assessment of bioavailable organic contaminants in aquatic environments. In Ostrander GK, ed, Techniques in Aquatic Toxicology. Lewis, New York, NY, USA, pp 625-655.

8. Hofelt CS. 1998. Use of artificial substrates to monitor organic contaminants in the aquatic environment. $\mathrm{PhD}$ thesis. North Carolina State University, Raleigh, NC, USA.

9. Luellen DR. 1999. Accumulation of PAHs and petroleum biomarkers in SPMDs and fish to discriminate petroleum sources. PhD thesis. Department of Toxicology, North Carolina State University, Raleigh, NC, USA.

10. Sabaliunas D. 1999. Semipermeable membrane devices in monitoring of organic pollutants in the aquatic environment (polyaromatic hydrocarbons, polychlorinated biphenyls, organochlorides). PhD thesis. Department of Ecology, Lund University, Lund, Sweden.

11. Petty JD, Orazio CE, Huckins JN, Gale RW, Lebo JA, Meadows JC, Echols KR, Cranor WL. 2000. Considerations involved with the use of semipermeable membrane devices for monitoring environmental contaminants. J Chromatogr A 879:83-95.

12. Rantalainen AL, Ikonomou MG, Rogers IH. 1998. Lipid-containing semipermeable membrane devices (SPMDs) as concentrators of toxic chemicals in the Lower Fraser River, Vancouver, British Columbia. Chemosphere 37:1119-1138.

13. Gale RW. 1998. Three-compartment model for contaminant accumulation by semipermeable membrane devices. Environ Sci Technol 32:2292-2300.

14. Heintz RA, Short JW, Rice SD. 1999. Sensitivity of fish embryos to weathered crude oil: Part II. Increased mortality of pink salmon (Oncorhynchus gorbuscha) embryos incubating downstream from weathered Exxon Valdez crude oil. Environ Toxicol Chem 18:494-503.

15. Bue BG, Sharr S, Moffitt SD, Craig AK. 1996. Effects of the Exxon Valdez oil spill on pink salmon embryos and preemergent fry. Am Fish Soc Symp 18:619-627.

16. Short JW, Jackson TJ, Larsen ML, Wade TL. 1996. Analytical methods used for the analysis of hydrocarbons in crude oil, tissues, sediments, and seawater collected for the natural resources damage assessment of the Exxon Valdez oil spill. Am Fish Soc Symp 18:140-148.

17. Carls MG, Rice SD, Hose JE. 1999. Sensitivity of fish embryos to weathered crude oil: Part 1. Low-level exposure during incubation causes malformations and genetic damage in larval $\mathrm{Pa}$ cific herring (Clupea pallasi). Environ Toxicol Chem 18:481493.

18. Short J, Heintz R. 1997. Identification of Exxon Valdez oil in sediments and tissues of PWS. Environ Sci Technol 31:23752384.

19. Kimura DK. 1992. Symmetry and scale dependence in functional relationship regression. Syst Biol 41:233-241.

20. Draper NR, Smith H. 1981. Applied Regression Analysis. John Wiley, New York, NY, USA, pp 129-133.

21. Carls MG, Hose JE, Thomas RE, Rice SD. 2000. Exposure of Pacific herring to weathered crude oil: Assessing effects on ova. Environ Toxicol Chem 19:1649-1659.

22. Lefkovitz L, Crecelius E, McElroy N. 1996. The use of SPMDs consisting of polyethylene alone to predict dissolved-phase organics in the Columbia River. Abstracts, 17th Annual Meeting SETAC. Washington, DC, USA, p 217.

23. Crunkilton RL, DeVita WM. 1997. Determination of aqueous concentrations of polycyclic aromatic hydrocarbons (PAHs) in an urban stream. Chemosphere 35:1447-1463.

24. Wang Y, Wang Z, Liu J, Ma M, Belzile N. 1999. Monitoring priority pollutants in the Yanghe River by dichloromethane extraction and semipermeable membrane device (SPMD). Chemosphere 39:113-131.

25. Sabaliunas D, Lazutka JR, Sabaliuniene I. 2000. Acute toxicity and genotoxicity of aquatic hydrophobic pollutants sampled with semipermeable membrane devices. Environ Pollut 109:251-265.

26. Livingston DR. 1991. Organic xenobiotic metabolism in marine invertebrates. In Gilles R, ed, Advances in Comparative and Environmental Physiology. Springer-Verlag, New York, NY, USA, pp 46-162.

27. Heard WR. 1991. Life history of pink salmon (Oncorhynchus gorbuscha). In Groot C, Margolis L, eds, Pacific Salmon Life Histories. University of British Columbia Press, Vancouver, BC, Canada, pp 121-230.

28. Petersen GI, Kristensen P. 1998. Bioaccumulation of lipophilic substances in fish early life stages. Environ Toxicol Chem 17: 1385-1395.

29. Meadows JC, Echols KR, Huckins JN, Borsuk FA, Carline RF, Tillitt DE. 1998. Estimation of uptake rate constants for PCB congeners accumulated by semipermeable membrane devices and brown trout (Salmo trutta). Environ Sci Technol 32:1847-1852.

30. Fent K, Baetscher R. 2000. Cytochrome P4501A induction potencies of polycyclic aromatic hydrocarbons in a fish hepatoma cell line: Demonstration of additive interactions. Environ Toxicol Chem 19:2047-2058

31. Gravato C, Santos MA. 2002. Juvenile sea bass liver P450, EROD induction, and erythrocytic genotoxic responses to PAH and PAHlike compounds. Ecotoxicol Environ Saf 51:115-127. 